\title{
LIÇÕES DA POLÍTICA NACIONAL DE INFORMÁTICA PARA UMA NOVA POLÍTICA INDUSTRIAL DE INTERNET DAS COISAS (Internet-of-Things - IoT)
}

\begin{tabular}{|c|c|}
\hline $\begin{array}{l}\text { ABEIN: Área } 6 \text { - Políticas Públicas e Regulação. } \\
\text { 6.2: Política de Ciência, Tecnologia e } \\
\text { Inovação }\end{array}$ & 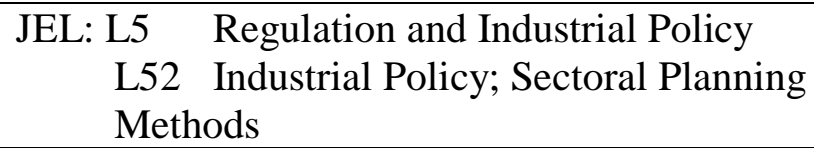 \\
\hline
\end{tabular}

\section{AUTORES:}

\begin{tabular}{|l|l|}
\hline Walter Shima & $\begin{array}{l}\text { Doutor pelo IE/UFRJ e Professor do Programa de Pós-graduação em Políticas } \\
\text { Públicas - UFPR. }\end{array}$ \\
\hline $\begin{array}{l}\text { Pollyanna } \\
\text { Rodrigues Gondin }\end{array}$ & $\begin{array}{l}\text { Mestre em Economia pelo PPGE/UFU e Doutora pelo Programa de Pós- } \\
\text { graduação em Políticas Públicas - UFPR, atualmente em pós-doutorado pelo } \\
\text { mesmo Programa. }\end{array}$ \\
\hline $\begin{array}{l}\text { Marcelo Castellano } \\
\text { Lopes }\end{array}$ & $\begin{array}{l}\text { Graduado em Economia pela UFPR e Mestrando do Programa de Pós-graduação } \\
\text { em Políticas Públicas - UFPR. }\end{array}$ \\
\hline Marcelo Vargas & $\begin{array}{l}\text { Mestre em Economia pelo PPGDE/UFPR e Doutorando do Programa de Pós- } \\
\text { graduação em Políticas Públicas - UFPR. Professor da UNESPAR - Campus de } \\
\text { Apucarana. }\end{array}$ \\
\hline
\end{tabular}

RESUMO: Embora existam discussões sobre uma política nacional de inovação, ainda há pouca discussão sobre uma política industrial focada em IOT. O objetivo do artigo é buscar na política nacional de informática, elementos institucionais de articulação de política pública que subsidiem uma proposta de política de IoT. Este artigo recupera a história da Política de Informática da década de 70 e 80 até seu abandonado na década de 90 , bem como a articulação e promoção das políticas pelo Estado. Foram apresentados dados da evolução da indústria de fabricação de equipamentos de informática e de desenvolvimento de software por meio da plataforma RAIS entre os períodos de 2006 e 2016. Os resultados obtidos nos mostram a presença de uma base industrial que possibilita um investimento inicial e uma alavancagem para a trajetória de desenvolvimento em IoT, principalmente no desenvolvimento de software. A discussão nos mostrou que se a Política de Informática não tivesse sido descontinuada nos anos 90, o Brasil poderia estar em um patamar mais elevado em relação a competitividade mundial. Assim, uma nova Política Nacional de IoT pode impulsionar o país como um importante player no setor de IoT. Por último, há uma análise do Estudo do BNDES que subsidia a Política Nacional de IOT.

Palavras-chave: Política Industrial, Política Pública, Internet das Coisas, Tecnologia da informação, BNDES.

ABSTRACT: Although there are discussions about a national innovation policy, there is still little discussion of an industrial policy focused on IOT. The objective of the article is to seek in the national policy of informatics, institutional elements of articulation of public policy that subsidize a proposal of IoT policy. This article recovers the history of Information Technology from the 1970s and 1980s until its abandonment in the 1990s, as well as the articulation and promotion of policies by the State. Data were presented on the evolution of the manufacturing industry of computer equipment and software development through the RAIS platform between the periods of 2006 and 2016. The results obtained show the presence of an industrial base that allows a leverage for the IoT development trajectory, mainly in software development. The discussion showed that if the Information Technology Policy had not been discontinued in the 1990s, Brazil could be at a higher level in relation to global competitiveness. Thus, a new National IoT Policy can boost the country as an important player in the IoT sector. Lastly, there is an analysis of the BNDES Study that subsidizes the National IOT Policy.

Keywords: Industrial Policy, Public Policy, Internet-of-Things, Information Technology, BNDES. 


\section{INTRODUÇÃO}

O objetivo deste artigo é buscar na Política Nacional de Informática dos anos 70/80 elementos institucionais de articulação de política pública que subsidiem uma suposta Política Nacional de IoT. Conforme se sabe, o Estado desempenhou papel relevante na articulação da política de informática. Esta política é estudada, porque se refere a uma atividade de natureza paradigmática tal como a atual IoT. Naquele momento dos anos 70/80 se tratava do surgimento de um novo paradigma tecnológico em que a entrada na "indústria" implicava necessariamente a atuação do Estado como elemento condutor das ações de estímulo, desenvolvimento e articulação entre os capitais privados (nacionais e multinacionais). $\mathrm{O}$ Estado brasileiro atuou de forma articulada em termos de criação de instituições e definição de forma de atuação em busca da criação e consolidação da "indústria nacional". Entretanto, como é sabido e será detalhado aqui, nos anos 80/90 essa organização da política foi perdendo seu folego em razão de erros e da prioridade macroeconômica, de tal forma que, a "indústria" brasileira de informática não se consolidou como um player relevante no cenário internacional.

O que se advoga aqui é que com o surgimento das tecnologias de IoT se abre uma nova corrida tecnológica com um conjunto de janelas de oportunidades de desenvolvimento "industrial" em que é possível novamente buscar a entrada e se tornar um competidor importante na corrida global. Para isso são necessárias ações efetivas de política industrial. Obviamente o cenário é absolutamente diferente e os competidores oriundos da "antiga" indústria de informática estão rapidamente diversificando suas atuações para essas novas atividades. Porém, na medida em que IoT implica intensidade do conhecimento, é possível trabalhar na perspectiva do desenvolvimento de soluções e atividades focadas na criatividade. Para isso será visto na seção 4, com base em dados da RAIS/MTE, que há uma base "industrial" importante no país com aptidão ao desenvolvimento de IoT. Trata-se de uma "indústria de Tecnologia da Informação (TI)" instalada no país, que durante o período 2006/16, se expandiu de forma importante, em termos de número de estabelecimentos, emprego e capacitação (que reflete a sua capacidade de absorção e produção de conhecimento novo).

$\mathrm{Na}$ tentativa de se iniciar uma política industrial de IoT, recentemente, o BNDES publicou 27 relatórios detalhando atividades e resultados diversos de pesquisa sobre esse tema. A metodologia de levantamento das informações baseou-se, fundamentalmente, na formação de painéis de especialistas, consultas públicas, entrevistas, além da realização de workshops. Tratou-se de uma pesquisa contratada por meio de edital em que foram vencedores o consórcio formado por McKinsey \& Company, Fundação CPqD e Pereira Neto Macedo Advogados. O estudo é extenso e apresenta uma série de dados relevantes. Como será visto tem um problema na sua origem que é não ter uma concepção de desenvolvimento nem tampouco de política industrial.

Desse modo, o artigo apresenta mais quatro seções além desta introdução e conclusão. A primeira seção fundamenta porque o Estado deve atuar como condutor das políticas e que somente a partir dessa visão é historicamente possível alcançar o desenvolvimento, demonstrando como a relação público/privada é fundamental. Na segunda seção é resgatada, como exemplo histórico, as características da Política Nacional de Informática, mostrando o papel do Estado liderando a Política. Na terceira seção são analisados alguns dados do que convém chamar aqui de "indústria de TI". Na quarta seção é feita uma avaliação do estudo do BNDES. Por último, apresenta-se a conclusão.

\section{ESTADO COMO ARTICULADOR E PROMOTOR DAS POLÍTICAS}

A política industrial é considerada um conjunto de ações que envolvem tanto o setor público como o privado e visa gerar progresso tecnológico, ampliar a competitividade da indústria, contribuir para o crescimento e desenvolvimento do país. Assim, considera-se a política industrial um dos temas-chave para o fortalecimento da indústria, de setores estratégicos, contribuindo para a elaboração de um projeto de desenvolvimento nacional. Segundo Kupfer (2003), cabe à política industrial, acelerar os processos de transformação produtiva que as forças de mercado podem operar de modo que políticas industriais bemsucedidas não se opõem ao mercado, mas ao mesmo tempo, também, não se limitam a complementá-lo, possuindo maior abrangência. 
Pode-se encontrar a mesma abordagem em Krugman (1989) que entende política industrial como um esforço do governo em desenvolver setores estratégicos para o desenvolvimento econômico. A ideia de desenvolver setores estratégicos se relaciona a setores chaves e teriam efeitos fundamentais e amplos para o desenvolvimento. Apesar de existirem abordagens contrárias ao desenvolvimento de políticas industriais, a experiência internacional mostra que todos os países praticam esse tipo de política, diferindo apenas em termos das estratégias e instrumentos utilizados, o grau de ativismo, as prioridades elencadas e o modo de coordenação do processo decisório (KUPFER, 2003). Chang (2002) nessa mesma linha, indica que os países desenvolvidos historicamente se utilizaram de diversos tipos de políticas industriais e agora estariam "chutando a escada" que significa que eles subiram e agora "chutam a escada" daqueles países que realizarem os mesmos tipos de políticas para não os ter em mesma condição de competitividade e desenvolvimento.

Mazzucato (2013) apresenta uma abordagem não apenas keynesiana, mas também schumpeteriana. A autora busca em seu livro desmistificar a falsa ideia de que a liberdade do setor privado irá revigorar os serviços. Essa falsa ideia é difundida uma vez que, segundo o senso comum, existe uma dicotomia entre um setor privado, revolucionário, dinâmico, inovador e competitivo versus um setor público burocrático, lento e atrasado. De acordo com a autora, o Estado não possui um bom departamento de marketing e que, portanto, seria necessário uma apresentação e conscientização do público sobre a história da tecnologia, reforçando o papel relevante desempenhado pelo Estado.

Destaca então o papel fundamental que o Estado desempenhou em processos de inovações, como no Vale do Silício, sendo nesse ator chave, não apenas por facilitar o processo de conhecimento e aprendizado, como também por atuar em investimentos específicos. A esse respeito, Mazzucato (2013) afirma ainda que as grandes inovações radicais ocorridas, como por exemplo, as ferrovias, o fenômeno da internet e a nanotecnologia, não seriam possíveis, sem a participação do Estado, por exemplo, no financiamento. Em casos de inovações radicais, a atuação do Estado é de grande relevância, já que as mesmas são arriscadas e com alto grau de incerteza. O Estado se mostra, portanto, como um parceiro importante do setor privado, parceiro este disposto a assumir os riscos que envolvem o processo inovativo.

Ao mesmo tempo, Mazzucato (2013) reforça que o papel do Estado não se limita à gestão da demanda keynesiana, sendo o mesmo visto também como um empresário, tomador de risco e criador de mercado. O Estado assume, papel primordial nos sistemas de inovação, facilitando o processo inovativo ao criar condições para que o mesmo ocorra. Levando em consideração que a difusão de inovações não é linear, os papéis da educação, formação, design, controle de qualidade e demanda efetiva assumem posições tão importantes quanto o sistema de P\&D (Pesquisa e Desenvolvimento) interno à empresa. $\mathrm{O}$ que mais uma vez, reforça a atuação do Estado na inovação.

Além disso, Mazzucato (2013) assegura que o Estado deve liderar o processo de desenvolvimento industrial e o desenvolvimento de áreas estratégicas, conduzindo o processo de industrialização. A defesa de um Estado mais atuante, segundo a autora, foi aceita em um consenso entre vários países que tentam recuperar seu atraso tecnológico em relação às economias mais desenvolvidas. Desse modo, o Estado atuaria não apenas na gestão da demanda keynesiana, mas também na condução do processo de industrialização. Para tanto, o Estado deve atuar levando em consideração as especificidades institucionais locais. Deve desenvolver políticas para o apoio ao aumento da capacidade tecnológica das empresas, incluindo, além do apoio ao financiamento das atividades de investigação e desenvolvimento, esquemas de incentivo e apoios na forma de serviço público.

Como exemplo Mazzucato (2013) analisa as economias asiáticas. De acordo com a autora, nos países mais atrasados industrialmente, o Estado coordenou a industrialização. Para tanto, assumiu funções de desenvolvimento, direcionou e escolheu setores para investimento, estabeleceu barreiras à concorrência estrangeiras, até que as empresas dos setores alvos se mostraram aptas a exportar seus produtos. Após essa fase, o Estado ainda foi importante ao prestar assistência em encontrar novos mercados para exportação. Ressaltando, mais uma vez a abordagem de Chang (2002), os países desenvolvidos nessa fase estariam "chutando a escada" nessa fase para que os países em desenvolvimento não a utilizem também para subir.

Outro exemplo da atuação do Estado no processo de industrialização, refere-se ao importante papel desempenhado por este ator no sucesso da Apple, nos Estados Unidos, frente a um discurso de livre mercado adotado por essa economia (MAZZUCATO, 2013). De acordo com a autora, a capacidade empreendedora, 
os conhecimentos técnicos e a genialidade de Steve Jobs foram relevantes para tal sucesso. Entretanto, os investimentos estatais em tecnologias deram a base que a Apple necessitava para o lançamento de seus produtos. Em vista disso, antes de lançar seus produtos mais populares da plataforma IOS, a Apple recebeu considerável apoio governamental direta e indiretamente através de três grandes áreas. A primeira referese ao investimento direto em patrimônio líquido durante os estágios iniciais de criação, risco e crescimento; a segunda, ao acesso a tecnologias que resultaram de programas governamentais de pesquisa, iniciativas militares, contratos de direito público, ou que foram desenvolvidos por instituições públicas de pesquisa; e a terceira diz respeito à criação de políticas fiscais, comerciais ou de tecnologia que permitiram sustentar seus esforços de inovação.

Assim, uma política industrial evolucionista pressupõe um Estado flexível, comprometido com os processos de mudança e que promova um ambiente favorável à exploração do novo. Ao mesmo tempo, é necessário que tal política leve em consideração as especificidades locais e institucionais. Assim, deve-se pensar política industrial focando na ação estatal, na concorrência e no progresso técnico. É por intermédio da ação do Estado nos ambientes de concorrência que se induz as empresas privadas a perseguirem estratégias de inovações (GADELHA, 2002).

Além disso, a atuação do Estado deve ter em conta também a informatização das sociedades e das economias, além da dinâmica global, para se implementar políticas tanto de âmbito nacional quanto regional e local. Ademais, a formação de blocos geopolíticos, de sistemas econômicos regionais, e a existência de instituições como a Organização das Nações Unidas (ONU) e o Fundo Monetário Internacional (FMI) irão influenciar diretamente a atuação do Estado e a elaboração de políticas públicas.

Na seção seguinte a partir da Política Nacional de Informática no Brasil nos anos 70/80 será mostrado que houve uma tentativa de uma atuação proativa do Estado brasileiro na criação e desenvolvimento de uma indústria chave para a nova dinâmica do crescimento econômico.

\section{POLITICA INDUSTRIAL E TRAJETÓRIA TECNOLÓGICA DO SETOR DE INFORMÁTICA NO BRASIL}

A ideia e criação de uma indústria nacional de informática no Brasil seguiu a tendência dos avanços tecnológicos mundiais que começou a ocorrer após o período da Segunda Guerra Mundial. A preocupação com esta indústria teve como iniciativa os interesses militares, uma vez que a importação de equipamentos de guerra de países estrangeiros, na década de 1970, demandava altos gastos. Deste modo, ressalta-se a importância dos fatores institucionais e das políticas públicas para o desenvolvimento e seleção de possíveis trajetórias, como nesse, aliando indústria de informática brasileira e atuação das Forças Armadas.

Evans (1995), afirma que, a visão de um setor de TI local começou com indivíduos convencidos do valor da produção local de informática e encontrou posições de influência no aparelho de Estado, sendo suas ideias transformadas em políticas e instituições destinadas a proporcionar a produção local. As políticas públicas do Estado brasileiro começaram em "incubadoras ou estufas" o que mostra o papel do Estado como "parteiro" (Estado promotor de novos grupos empresariais ou indutor de grupos já existentes, na qual pode utilizar políticas protecionistas, barreiras tarifárias, subsídios, dentre outros) e a sua finalidade de proteger os empresários locais.

É preciso levar em consideração que na década de 1960, descontos fiscais e liberdade de importação foram introduzidos para os japoneses e outras empresas que queriam montar fábricas de eletrônicos no país. Além disso, a Zona Franca de Manaus desenvolveu-se em uma "plataforma de importação", o que causou a inundação do mercado brasileiro com produtos estrangeiros e minou o potencial industrial local do país na produção de produtos de informática (EVANS, 1995).

\subsection{A CRIAÇÃO DA POLÍTICA DE INFORMÁTICA NA DÉCADA DE 70: PAPEL ATIVO DO ESTADO E ARTICULAÇÃO INSTITUCIONAL}

Na primeira metade da década de 1970, o milagre econômico brasileiro produziu a confiança geral de que uma transformação industrial era possível, por meio, principalmente, do II PND (Plano Nacional de Desenvolvimento) que enfatizou o aprofundamento da capacidade industrial brasileira e expandiu o papel do capital local. Apesar da dominante ideologia do livre mercado, tecnocratas simpatizantes com a política 
industrial de cunho nacionalista ganharam espaço entre os formuladores de políticas. Evans (1995) também enfatiza que a indústria de armas brasileira, liderada por empresas estatais contribuiu de forma significativa para o desempenho das exportações. Outra questão relevante é que a política de informática foi formulada durante o governo militar, o que a tornou uma importante fonte de poder político. Como afirmado anteriormente, o governo brasileiro optou por uma estratégia do tipo "parteira", porém, como o autor salienta, as possibilidades de uma estratégia do tipo "parteira" iam contra a internacionalização do país e como a indústria de computadores, assim como as indústrias intensivas em tecnologia, era dominada por capital estrangeiro, a ideia de implantar uma indústria intensiva tecnologicamente e autossuficiente, parecia completamente fantasiosa.

Pode-se considerar então que a política brasileira de informática começou a ser delineada no início da década de 1970, sendo que em março de 1971, através de um contrato entre a Marinha, o Ministério do Planejamento e universidades, foi criado o projeto GTE/FUNTEC 111 (Grupo de Trabalho Especial Fundo Tecnológico) com o orçamento inicial de US\$ 2 milhões que teve como resultado a construção do minicomputador G-10 com o hardware desenvolvido pela Politécnica Universidade de São Paulo (USP) e o software pela Pontifícia Universidade Católica do Rio de Janeiro (PUC-RJ) (TIGRE, 1993).

Em 1972, foi criada a CAPRE (Comissão de Coordenação de Processamento Eletrônico), sendo responsável por colocar em prática políticas governamentais para o setor de informática. A CAPRE era presidida pelo Ministério do Planejamento, e possuía representantes das Forças Armadas, do Ministério da Fazenda, BNDE ${ }^{1}$ (Banco Nacional de Desenvolvimento Econômico), SERPRO (Serviço Federal de Processamento de Dados), IBGE (Instituto Brasileiro de Geografia e Estatística) e Escritório da Reforma Administrativa. Uma das diretrizes dessa Comissão e que mais tarde se tornou o eixo central da Política Nacional de Informática era a "capacitação de organizações industriais brasileiras no desenvolvimento e fabricação dos equipamentos (hardware)" (FAJNZYLBER, 1993, p. 5).

\begin{abstract}
A consecução de políticas mais ativas, no entanto, só viria a ser possibilitada pela ampliação dos poderes e atribuições da CAPRE que, no final de 1975 e início de 1976, seria dotada tanto dos instrumentos necessários à execução dessas políticas, quanto da explícita incumbência de formalizar critérios concretos para o uso desses instrumentos. Com efeito, no bojo das medidas de restrição às importações que o governo estava implementando para paliar as dificuldades no balanço de pagamentos brasileiro provocadas pelo primeiro "choque do petróleo", o Conselho Nacional de Comércio Exterior (CONCEX) estabeleceria, em dezembro de 1975, a necessidade de anuência prévia, a ser concedida pela CAPRE, para a importação de computadores e periféricos, assim como das suas partes, peças e componentes. Poucos meses depois, em fevereiro de 1976, a CAPRE tinha sua composição alterada e recebia a atribuição de "propor as diretrizes da Política Nacional de Informática" (FAJNZYLBER, 1993, p. 6).
\end{abstract}

Nesse mesmo período foi proposta a criação de um instrumento de intervenção estatal, com o intuito de estimular o desenvolvimento da eletrônica no país. Surgiu então, em 1972, a Eletrônica Digital Brasileira Ltda., sendo logo em seguida estatizada e chamada de DIGIBRÁS/SA que tinha como função possibilitar que o BNDE e demais instituições governamentais participassem da constituição das empresas nacionais de computadores.

Em 1973, diante da Crise do Petróleo, o governo resolveu atuar de modo a solucionar problemas como o déficit nas importações. Desse modo, criou a Política Nacional de Informática optando pela criação de indústrias locais de computadores. Assim, em 1974, foi fundada a empresa nacional de Computadores e Sistema Brasileiro Ltda. (COBRA), que contou com a participação acionária da DIGIBRÁS, da Ferranti inglesa e da EE Equipamentos Eletrônicos (empresa privada nacional). A ideia inicial era produzir o Argus 700, um minicomputador projetado para aplicações de controle e processo. Apesar de ter sido criada em 1974, tanto os parceiros quanto as tecnologias escolhidas mostravam-se inadequadas, de modo que a COBRA só se tornou cem por cento operacional no ano de 1977 (FAJNZYLBER, 1993).

1 Criado em 1952 pela Lei $\mathrm{n}^{\mathrm{o}} 1.628$ tinha como objetivo ser o órgão formulador e executor da política nacional de desenvolvimento econômico. O início dos anos 80 foi marcado pela integração das preocupações sociais à política de desenvolvimento do Brasil. Assim, em 1982 o Banco passou a se chamar BNDES (Banco Nacional de Desenvolvimento Econômico e Social.) 
Neste ano, após sucessivas injeções de recursos realizadas pelo BNDE (o sócio nacional mostrou, desde o início, sua incapacidade de contribuir à capitalização do empreendimento), constituía-se um consórcio formado por treze instituições financeiras nacionais que passavam a deter 39\% do capital da COBRA, enquanto outros 39\% eram assumidos pelo SERPRO, o Banco do Brasil e a Caixa Econômica Federal: o patrimônio da COBRA passava de 4,4 para 30,8 milhões de dólares. No mesmo período, a linha de produtos da empresa era fortalecida com a assinatura de um novo contrato de transferência de tecnologia, desta vez referente a um minicomputador de uso geral que, à diferença do produto da Ferranti, possuía um significativo mercado comercial - era o modelo 400 da Sycor, americana (FAJNZYLBER, 1993, p. 8).

Até 1975 predominava no país empresas multinacionais de computação, de modo que os negócios das multinacionais aumentavam em ritmo acelerado. Assim, houve crescimento do parque instalado de computadores e a IBM "apesar de manter a sua liderança em termos de valor (dos equipamentos instalados), caía para o terceiro lugar em termos do número de máquinas em funcionamento, atrás da Burroughs e da Olivettí" (FAJNZYLBER, 1993, p. 9). Como a IBM gostaria de reassumir a liderança em termos do número de máquinas em funcionamento, anunciou a fabricação do System/32, além de utilizar-se de pressões políticas e de uma campanha de marketing agressiva.

Apesar disso, visando proteger a indústria nacional, adotou-se no Brasil uma política protecionista à indústria de informática com a finalidade de desenvolver a indústria de computadores brasileira, estimulando a fabricação local por subsidiárias multinacionais. Segundo Fajnzylber (1993), visava-se interromper a fabricação do System/32 pela IBM (a IBM não tinha autorização oficial e declarava o valor importado por meio de guias genéricas de importação para não detalhar o que estava sendo importado).

Em 1977 foi fixada uma resolução do CDE (Conselho de Desenvolvimento Econômico), com a finalidade de orientar os órgãos governamentais na concessão de incentivos fiscais e na aprovação de pedidos de importação de peças e componentes para a fabricação de computadores no Brasil. Esta resolução possuía cinco pontos, a saber:

1. Grau de abertura tecnológica e absorção de tecnologia, dando-se prioridade às empresas que estivessem estruturadas de forma a recorrer à engenharia nacional para conceber e projetar seus novos produtos e técnicas de produção;

2. Índices de nacionalização, com prioridade para as empresas sem vínculo permanente com fornecedores no exterior que pudesse dificultar uma nacionalização mais efetiva dos seus produtos;

3. Participação da empresa no mercado interno, visando evitar o estabelecimento de um grau excessivo de concentração da produção;

4. Participação acionária nacional;

5. Balanço de divisas, dando-se prioridade às empresas que apresentassem perspectivas mais favoráveis ao País (FAJNZYLBER, 1993, p. 11).

Então, iniciou-se nesse período, a política de Reserva de Mercado para a informática no Brasil, atuando no controle das importações e das ações das subsidiárias das multinacionais no país, além de atuar no estímulo a criação de empresas nacionais de minicomputadores e periféricos. Assim, de acordo com Fajnzylber (1993), em 1977 a CAPRE emitiu um parecer favorável ao projeto COBRA de fabricar o Sycor 400, e contrário à fabricação do sistema da IBM. Diante da recusa ao System/32 da IBM, foi lançada uma concorrência nacional para o segmento de minicomputadores, sendo que ao final foram escolhidas três empresas de capital 100\% nacional e tecnologia licenciada. As três empresas eram: Sharp/Inepar/Dataserv com tecnologia da Logabax francesa, a Edisa com tecnologia da Fujitsu japonesa e a Labo com tecnologia da Nixdorf alemã.

Já em 1979, os órgãos governamentais responsáveis pelo setor de informática no país passaram por um processo de reestruturação. Neste processo, a CAPRE foi substituída pela SEI (Secretaria Especial de Informática), ligada ao Conselho de Segurança Nacional, que deu novo enfoque ao setor, afirmando a supremacia militar frente ao BNDE e ao Ministério do Planejamento. O setor de informática passou então, a ser considerado um setor estratégico (RODRIGUES, 2004).

Apesar de existirem outras empresas no setor, era a empresa COBRA que liderava o mercado, desenhando os rumos que deveriam ser seguidos pelas demais empresas nacionais de computador, tanto no 
que diz respeito à preparação de mão-de-obra quanto nos avanços tecnológicos. Essa atuação da COBRA foi relevante logrando realizações tecnológicas e atendimento ao mercado interno (TIGRE, 1993).

No que diz respeito ao atendimento ao mercado interno, faz-se necessário ressaltar que a indústria nacional estava voltada para a produção de minicomputadores e periféricos, enquanto multinacionais como a IBM, a Burroughs e a Hewlett-Packard, se encarregavam da produção de computadores de maior porte (Alder, 1986). Um dos sucessos brasileiros à época foi o desenvolvimento total de um computador de médio porte, o modelo COBRA 530 e o desenvolvimento do sistema operacional CYSNE 2.0, modelo similar ao MS-DOS (Microsoft Disk Operating System). No que diz respeito ao sucesso do setor de informática do país, deve-se considerar que o mesmo estava relacionado com duas formas de atuação do Estado: a primeira se refere aos investimentos feitos na empresa estatal COBRA, que garantia um programa de P\&D; e a segunda diz respeito à proteção ao mercado interno dos computadores brasileiros com o estabelecimento do contrato entre a sociedade e o governo, contrato este fundamentado na ideia de soberania nacional.

\subsection{POLÍTICA DE INFORMÁTICA NA DÉCADA DE 80: TENTATIVA DE INTENSIFICAÇÃO DA POLÍTICA INDUSTRIAL E ERROS DA TRAJETÓRIA TECNOLÓGICA}

Em outubro de 1984 foi sancionada a Lei da Informática, que de modo resumido, significava a consolidação da política que estava sendo implementada até o momento. O objetivo para a Política Nacional de Informática era "a capacitação nacional nas atividades de informática, em proveito do desenvolvimento social, cultural, político, tecnológico e econômico da sociedade brasileira (artigo $2^{\circ}$ da Lei $N^{o} 7.232 / 84$ ) (Fajnzylber, 1993, p. 21). Apesar de seguir a mesma linha da política que vinha sendo implementada desde os tempos da CAPRE, a Lei propunha modificações no arcabouço institucional. Assim, as funções de caráter normativo passaram a ficar sob a responsabilidade do CONIN (Conselho Nacional de Informática e Automação). Este Conselho tinha como uma de suas funções, propor, a cada três anos, o PLANIN (Plano Nacional de Informática e Automação).

Em abril de 1986 foi aprovado o I PLANIN, através da Lei $n^{\circ} 7.463$, que em sua essência, estabelecia critérios para a execução da Política de Informática por um período de três anos. A partir de dezembro de 1985, os incentivos previstos na Lei foram regulamentados. Dentre estes incentivos é possível citar: isenção ou redução do Imposto de Importação, isenção do Imposto de Exportação, isenção ou redução do IPI (Imposto sobre Produtos Industrializados), isenção ou redução do IOF (Imposto sobre Operações de Crédito, Câmbio e Seguro, ou Relativo a Títulos Mobiliários), dentre outros. Como compensação à concessão dos incentivos, foi fixado em " $10 \%$ o percentual obrigatório de investimento em P\&D das receitas de comercialização obtidas pelas empresas beneficiárias na área da informática" (FAJNZYLBER, 1993, p. 26).

O segmento industrial mais beneficiado com os incentivos fiscais, foi o da microeletrônica, sendo que das 50 empresas beneficiadas entre os anos de 1986 e 1987, 93\% pertenciam a esse segmento. Entretanto, como afirma Fajnzylber (1993), os incentivos que de fato foram apropriados, eram inferiores aos que foram autorizados. Além disso, o autor afirma que a participação do governo no financiamento da indústria de informática e na compra de bens produzidos pelas empresas nacionais, foi tardia e de pequeno monte. Ademais, o país não possuía e nem desenvolveu uma infraestrutura de ciência e tecnologia expressiva.

Assim, a partir da segunda metade da década de 1980, a articulação em torno do interesse nacional foi perdendo força, já que a indústria nacional se tornou defasada em relação ao restante do mundo, uma vez que não conseguia se manter atualizada com relação à revolução da microeletrônica que acontecia nos países desenvolvidos. Além disso, a COBRA, empresa que articulava todo o setor, passava por problemas internos relacionados às finanças e desestímulos dos funcionários. Outra questão relevante que merece ser destacada e que se refere a trajetória tecnológica do setor de informática brasileiro, diz respeito a nova natureza dos fundamentos das políticas públicas: trata-se de um momento da história, claramente sabido em que o desenvolvimentismo passa a perder espaço pela visão neoliberal e o Estado, muda o rumo de desenvolvimento da trajetória do setor de informática brasileiro. 


\subsection{O FIM DA POLÍTICA DE INFORMÁTICA A PARTIR DA DÉCADA DE 90: NEOLIBERALISMO E DESMONTE DO ESTADO}

Em 1991, o então presidente Fernando Collor, acabou com a Política de Informática, colocando fim aos aparatos institucionais e aos instrumentos da política. Desse modo, o protecionismo adotado pelo país na década de 1970, para estimular o seu desenvolvimento tecnológico, foi barrado pela abertura comercial iniciada na década de 1990, o que revelou a fragilidade da Política de Informática brasileira frente aos mesmos tipos de políticas que funcionavam nos países desenvolvidos (TIGRE, 1993).

A partir de então, de acordo com Tigre (1993), a sobrevivência das empresas brasileiras de informática passou a estar condicionada à alteração na forma de atuação, seja reformulando suas estratégias, buscando novos parceiros, direcionando a produção para outros segmentos de atuação ou mesmo abandonando o mercado. Assim, as empresas nacionais que permaneceram no mercado de informática reduziram suas atividades de desenvolvimento e passaram a atuar em novos nichos de mercado. Além disso, deve-se ressaltar também que com a abertura do mercado, as empresas passaram a adquirir do exterior tecnologia e produtos para a montagem de computadores internamente, diminuindo os gastos com $\mathrm{P} \& \mathrm{D}$ das empresas brasileiras em cerca de $70 \%$.

Portanto, atuar no mercado de computadores pessoais tornou-se cada vez mais difícil para as empresas nacionais, devido, principalmente, ao intenso ritmo de inovação e a significativa redução de custos que ocorria por parte das empresas multinacionais tanto no país como no exterior. As multinacionais começam a ditar os padrões tecnológicos globais por meio de sistemas proprietários, com os quais seria impossível passar a concorrer ou estabelecer alguma capacidade competitiva em condições de igualdade. A fraca indústria nacional deveria buscar as limitadas alternativas de mercados e consequentemente tecnológicas. Para fazer frente a isso seria necessária uma articulação tecnológica e a formação de redes por parte dos fabricantes, encontrando assim, as vocações no setor de informática articuladas por uma perspectiva de formação de um sistema nacional e/ou setorial de inovação. Algo de forma tímida ainda há na irrelevante política industrial do país.

\section{PERSPECTIVAS DE UMA POLÍTICA INDUSTRIAL VERTICAL COM FOCO EM IoT}

Esse levantamento sobre a história econômica recente a respeito de uma política industrial no Brasil, mostra que a decisão de se desenvolver uma indústria nacional de informática dependeu de uma decisão proativa do Governo, o que significou uma articulação nacional de diversas instituições no âmbito do setor público e a criação de condições institucionais/legais de natureza política e consequentemente uma estrutura de poder em meio às diversas áreas envolvidas. Em outros termos, a possibilidade de se desenvolver uma indústria nacional não decorreria de políticas eventuais ou apenas do livre jogo competitivo do mercado, mas, de uma ação explicita de natureza política, econômica e jurídica/institucional. É verdade que o abandono ou a devida importância não foi dada durante os anos 80 em função da busca do exclusivo ajuste macroeconômico de combate à inflação e o abandono oficial no início dos anos 90 condenou definitivamente a entrada do Brasil na concorrência global do novo paradigma tecnológico. Se ao contrário, a política de informática tivesse tido uma sequência, teria sido possível encontrar algum lugar na divisão global da produção de TIs, como fez a Coréia do Sul. Nos anos 70/80 este país se encontrava em condições inferiores ao Brasil em termos de desenvolvimento tecnológico e já no final dos anos 90 se tornava um player internacional no nicho de televisores, monitores de vídeo e outros segmentos das TIs. Numa simples analogia, o Brasil abandonou a corrida global das TIs no meio do caminho, enquanto a Coréia do Sul permaneceu. Esta última não chegou necessariamente ao topo do pódio, mas alcançou e permanece nele em alguma posição importante.

Mundialmente, naquele momento dos anos 70/80 a indústria de TI não estava consolidada ainda. Não haviam players importantes já estabelecidos e cada player adotava sua estratégia empresarial, de mercado e tecnológica. Haviam vários padrões de sistemas operacionais proprietários, processadores autofabricados, monitores dos mais diversos, entre outros. Todo competidor buscava algum diferencial de preço e amigabilidade no uso dos equipamentos. A corrida se dava tanto em termos de hardware como de software e a grande questão competitiva era se tornar o padrão do mercado e consequentemente, criar externalidades de rede. Desse modo, nos anos 90, dada as diversas estratégias das firmas, com forte apoio dos Estados nacionais, se consolidou o padrão Intel-Microsoft-IBM e os demais competidores tiveram que 
se rearranjar nos diversos nichos possíveis dentro desse padrão, ao mesmo tempo em que, muitas simplesmente deixaram o mercado, como por exemplo, Remington-Rand, Radio Shack, Olivetti, MicroPro International, Sorcim, Borland, entre outras. Mas conforme já visto anteriormente, destaca-se novamente a visão de Mazzucatto (2013) em que os Estados Nacionais atuaram pró-ativamente em fortalecer seus "atuais campeões nacionais".

Os players da atual indústria de TI já estão consolidados e a entrada como player global de alguma firma em algum dos seus nichos é praticamente bloqueada. Além disso, essa entrada implicaria fazer mais do mesmo, apenas com inovações incrementais. Os Estados Nacionais já têm claro que políticas industriais de entrada nesta indústria serão inócuas e que se trata de uma indústria cujos líderes já estão consolidados.

A atual dinâmica de desenvolvimento tecnológico tem radicalizado o desenvolvimento da informática, na medida em que os processadores são incorporados a todos os objetos que podem se comunicar pela internet por meio de um protocolo de comunicação padrão. É radical em função de que os processadores são cada vez menores e com maior capacidade de comunicação a custos decrescentes. Uma vez que, tudo se comunica com tudo numa única rede por meio de protocolo padrão (em que também players globais disputam em impor o seu padrão), a consequência imediata é a criação de uma crescente base de dados. Processadores junto com sensores incorporados aos objetos podem prever e antecipar uma série de acontecimentos em todas áreas da vida humana. Cada vez mais será possível gerar banco de dados para todo tipo de atividade e controle das ações humanas e dos objetos.

Do ponto de vista do desenvolvimento industrial trata-se da Indústria 4.0. A Figura 1 ilustra porque é denominada Indústria 4.0.

\section{FIGURA 1-DA INDÚSTRIA 1.0 Á INDÚSTRIA 4.0}

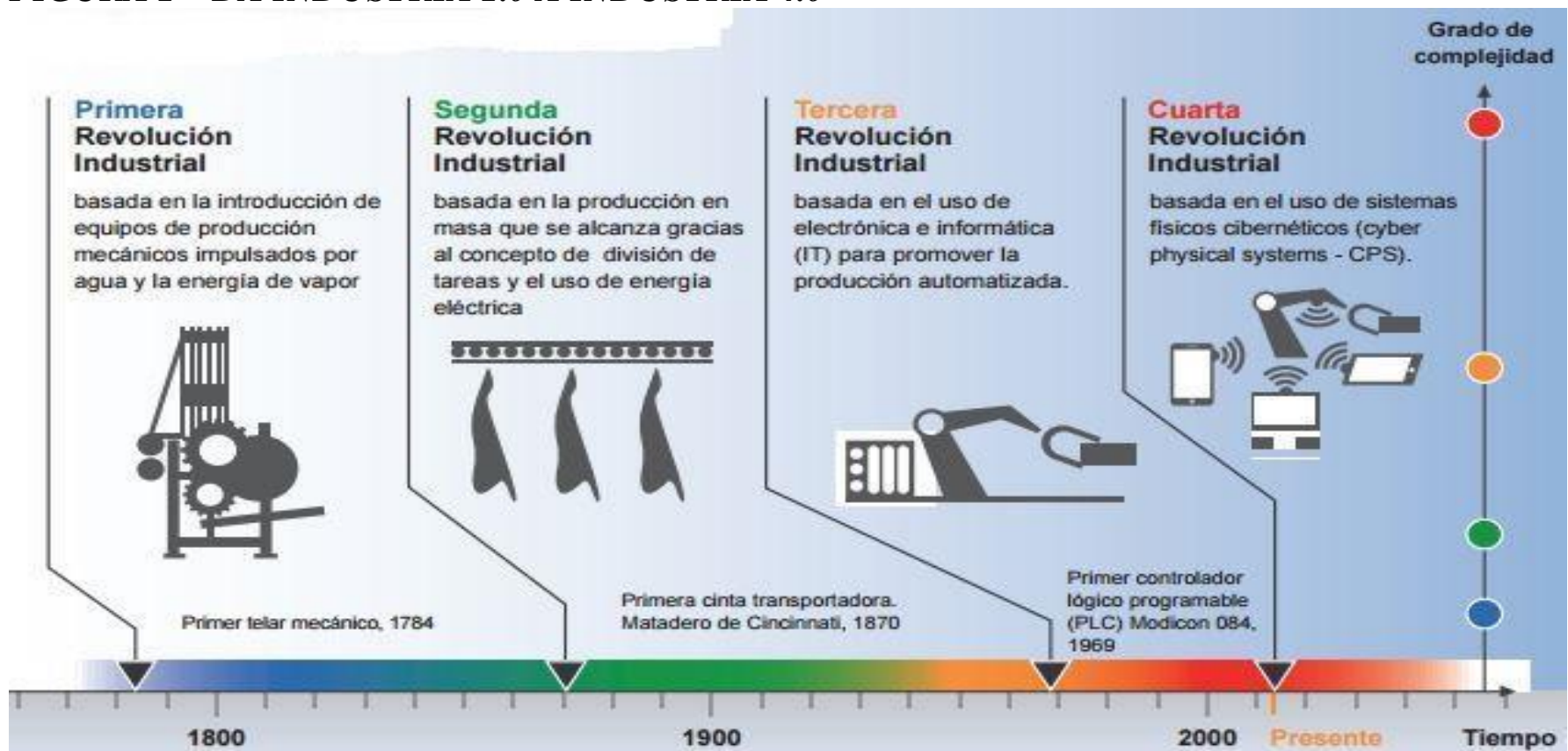

Fonte: http://grupofranja.com/index.php/oftalmica/item/1763-de-la-industria-1-0-a-la-4-0. Acesso em 20/04/18.

De acordo com Hermann et al. (2015) citado por Furtado (2017):

Indústria 4.0 é um termo coletivo para tecnologias e conceitos da organização da cadeia de valor. No interior das fábricas inteligentes e modulares da Indústria 4.0, sistemas ciber-físicos (CPS) monitoram processos, criam uma cópia virtual da realidade e tomam decisões descentralizadas. Através da Internet das Coisas (IoT) os CPS se comunicam e cooperam entre si e com seres humanos em tempo real, e através da Internet dos Serviços (IoS) são oferecidos serviços organizacionais internos e externos, utilizados por participantes desta cadeia de valor.

É possível, portanto, perceber que se trata de uma indústria ainda na sua gestação e que, consequentemente, não há players líderes nos moldes desenvolvidos na "antiga" indústria de informática. As possibilidades de desenvolvimentos a partir da IoT não estão totalmente apropriadas, mesmo que os 
“antigos" possam diversificar para esse novo segmento e já estabelecem estratégias pesadas de domínio e imposição de padrões. Essas possibilidades estão mais amplamente ligadas à criatividade no desenvolvimento de soluções e ideias que levam a automações e maior interação homem-máquina. Consequentemente os mecanismos de barreiras à entrada não estão plenamente definidos. Dado o elevado grau de incerteza, os competidores ainda estão se configurando com base em suas expectativas tecnológicas, de mercado e regulatória ${ }^{2}$.

Portanto, da mesma forma que nos anos 70/80 se abriu uma janela de oportunidades de desenvolvimento industrial com a informática que foi pouco aproveitada pela política industrial no Brasil, a IoT é uma nova janela aberta com amplas possibilidades de entrada. Trata-se de uma nova corrida em que o Brasil tem condições novamente de participar em condições competitivas consideráveis, uma vez que, os elementos característicos dessa nova corrida estão ligados aos elementos citados acima de criatividade. A base industrial é importante na sua aplicabilidade e desenvolvimento, mas o aspecto importante é que os segmentos possíveis de se voltarem para o desenvolvimento de IoT têm se expandido de forma importante no país. A seguir será apresentado uma suposta base industrial disponível no Brasil que podem vir ou já desenvolvem IoT.

\subsection{A EVOLUÇÃO DOS SEGMENTOS DA CNAE ${ }^{3}$ COMO POSSÍVEIS DESENVOLVEDORES DE IoT}

A ideia nesta seção é analisar o comportamento do número de estabelecimentos, emprego e qualificação dos dados da RAIS da Divisão 26 (Fabricação de Equipamentos de Informática, Produtos Eletrônicos e Ópticos) e Classes 6201-5; 6202-3; 6203-1 da Divisão 62 (Atividades dos Serviços de Tecnologia da Informação) que são as classificações assumidas aqui como os segmentos com amplo potencial de se tornarem ou desenvolverem atividades de IoT. Qual é a dimensão dessas atividades no Brasil? Há uma base industrial importante?

Conforme as Tabela 1 eTabela 2 no período 2006/16 as Micro e Pequenas empresas representaram mais de $90 \%$ do total de estabelecimento no início e no final do período. Na Divisão 26 há relativa estabilidade na Taxa de Crescimento Acumulado Composto (TCAC ${ }^{4}$ do número de estabelecimentos considerando os baixos e até negativos valores das TCAC por tamanho de empresas.

Tabela 1 - Número de Estabelecimentos na Divisão 26 - Fabricação de Equipamentos de Informática, Produtos Eletrônicos e Ópticos - 2006-2016

\begin{tabular}{l|c|c|c|c|c}
\hline Tamanho & $\mathbf{2 0 0 6}$ & $\mathbf{\%}$ & $\mathbf{2 0 1 6}$ & $\mathbf{\%}$ & TCAC \\
\hline Micro & 2.160 & $71,19 \%$ & 2.532 & $74,89 \%$ & $1,46 \%$ \\
\hline Pequena & 616 & $20,30 \%$ & 636 & $18,81 \%$ & $0,29 \%$ \\
\hline Média & 211 & $6,95 \%$ & 181 & $5,35 \%$ & $-1,38 \%$ \\
\hline Grande & 47 & $1,55 \%$ & 32 & $0,95 \%$ & $-3,43 \%$ \\
\hline Total & $\mathbf{3 . 0 3 4}$ & $\mathbf{1 0 0 , 0 0 \%}$ & $\mathbf{3 . 3 8 1}$ & $\mathbf{1 0 0 , 0 0 \%}$ & $\mathbf{0 , 9 9 \%}$ \\
\hline
\end{tabular}

Fonte: Elaboração pelos autores com base na RAIS-MTE.

Por outro lado, nas Classes (Tabela 2) estudadas há expansão importante do número de estabelecimentos que podem ser mais ou menos correlacionados ao tamanho. Ou seja, o número de empresas cresce mais na medida em que aumenta o tamanho. Vide por exemplo, a TCAC das Micros $(8,83 \%)$ comparativamente a das Grandes $(13,54 \%)$. A ideia sintética a partir desses dados é que tende a crescer mais as atividades relacionadas ao conhecimento e criatividade (software) do que as atividades de

2 Dado o caráter de novidade ainda os processos regulatórios por parte dos Estados Nacionais também são incertos. Nem mesmo se tem muito claro sobre o que e muito menos como deve ser a regulação.

3 Classificação Nacional de Atividades Econômicas.

4

Onde $\mathrm{n}=$ número de períodos .

$$
T C A C=\left[\frac{\text { valor final }}{\text { valor inicial }}\right]^{\frac{1}{n}}-1
$$


produção que não necessariamente têm um mesmo grau de exigência do conhecimento. As atividades de produção como, se nota na Tabela 1, são atividades em declínio em termos de número de estabelecimentos.

Da mesma forma que na Tabela 1 a TCAC do emprego nesta mesma Divisão 26 também permaneceu relativamente estável e também da mesma forma que na Tabela 2 o emprego cresceu de forma significativa nas Classes.

Tabela 2 - Número de Estabelecimentos nas Classes 6201-5; 6202-3; 6203-1 - Desenvolvimento de Softwares - 2006-2016

\begin{tabular}{l|c|c|c|c|c}
\hline Tamanho & $\mathbf{2 0 0 6}$ & $\mathbf{\%}$ & $\mathbf{2 0 1 6}$ & \% & TCAC \\
\hline Micro & 2.419 & $75,31 \%$ & 6.138 & $71,58 \%$ & $8,83 \%$ \\
\hline Pequena & 608 & $18,93 \%$ & 1.818 & $21,20 \%$ & $10,47 \%$ \\
\hline Média & 111 & $3,46 \%$ & 320 & $3,73 \%$ & $10,10 \%$ \\
\hline Grande & 74 & $2,30 \%$ & 299 & $3,49 \%$ & $13,54 \%$ \\
\hline Total & $\mathbf{3 . 2 1 2}$ & $\mathbf{1 0 0 , 0 0 \%}$ & $\mathbf{8 . 5 7 5}$ & $\mathbf{1 0 0 , 0 0 \%}$ & $\mathbf{9 , 3 4 \%}$ \\
\hline
\end{tabular}

Fonte: Elaboração pelos autores com base na RAIS-MTE.

Considerando a Tabela 1, na qual houve uma pequena evolução $(0,99 \%)$ no número de estabelecimentos na Divisão 26, pode-se perceber através da Tabela 3 que está evolução não impactou no número de vínculos ativos, pois a variação foi negativa $(-1,08 \%)$. Este resultado é melhor percebido na Tabela 5 mais abaixo, onde o grau de escolaridade foi negativo onde há menor instrução e positivo onde há maior instrução, mostrando uma mudança de perfil da mão de obra.

Tabela 3 - Número de Vínculos Ativos na Divisão 26 - Fabricação de Equipamentos de Informática, Produtos Eletrônicos e Ópticos - 2006-2016

\begin{tabular}{l|c|c|c|c|c}
\hline Tamanho & $\mathbf{2 0 0 6}$ & $\mathbf{\%}$ & $\mathbf{2 0 1 6}$ & \% & TCAC \\
\hline Micro & 12.988 & $9,24 \%$ & 13.886 & $11,14 \%$ & $0,61 \%$ \\
\hline Pequena & 26.875 & $19,13 \%$ & 27.669 & $22,19 \%$ & $0,27 \%$ \\
\hline Média & 44.535 & $31,70 \%$ & 38.907 & $31,20 \%$ & $-1,22 \%$ \\
\hline Grande & 56.112 & $39,93 \%$ & 44.241 & $35,48 \%$ & $-2,14 \%$ \\
\hline Total & $\mathbf{1 4 0 . 5 1 0}$ & $\mathbf{1 0 0 , 0 0 \%}$ & $\mathbf{1 2 4 . 7 0 3}$ & $\mathbf{1 0 0 , 0 0 \%}$ & $\mathbf{- 1 , 0 8 \%}$ \\
\hline
\end{tabular}

Fonte: Elaboração pelos autores com base na RAIS-MTE.

Observando as Tabelas 3 e 4, em 2006 o emprego na Divisão 26 era 2,5 vezes o emprego nas Classes e dada a TCAC Total de 10,89\% (nas Classes) no período, o emprego nas Classes superou a Divisão 26. Mais um elemento que evidencia que as atividades mais intensivas em conhecimento são as que mais desenvolvem na "indústria de TI".

Tabela 4 - Número de Vínculos Ativos nas Classes 6201-5; 6202-3; 6203-1 - Desenvolvimento de Softwares - 2006-2016

\begin{tabular}{l|c|c|c|c|c}
\hline Tamanho & $\mathbf{2 0 0 6}$ & $\mathbf{\%}$ & $\mathbf{2 0 1 6}$ & $\mathbf{\%}$ & TCAC \\
\hline Micro & 6.295 & $11,42 \%$ & 17.620 & $10,26 \%$ & $9,81 \%$ \\
\hline Pequena & 12.743 & $23,13 \%$ & 37.371 & $21,76 \%$ & $10,28 \%$ \\
\hline Média & 7.549 & $13,70 \%$ & 22.239 & $12,95 \%$ & $10,32 \%$ \\
\hline Grande & 28.514 & $51,75 \%$ & 94.477 & $55,02 \%$ & $11,51 \%$ \\
\hline Total & $\mathbf{5 5 . 1 0 1}$ & $\mathbf{1 0 0 , 0 0 \%}$ & $\mathbf{1 7 1 . 7 0 7}$ & $\mathbf{1 0 0 , 0 0 \%}$ & $\mathbf{1 0 , 8 9 \%}$ \\
\hline
\end{tabular}

Fonte: Elaboração pelos autores com base na RAIS-MTE.

Outro elemento relevante que demonstra a expansão da "Indústria de TI" no país é a melhoria da qualificação da mão-de-obra. Isso reflete a capacidade de absorver, aprender e desenvolver P\&D. Conforme a Tabela 5 percebe-se o decréscimo das TCAC dos estratos menos qualificados e crescimentos das TCAC dos extratos mais qualificados. Apesar de que ainda o estrato Médio (completo e incompleto) seja o maior empregador em termos absolutos, houve expansão significativa de Mestrado e Doutorado. 
Tabela 5 - Grau de Escolaridade na Divisão 26 - Fabricação de Equipamentos de Informática, Produtos Eletrônicos e Ópticos - 2006-2016

\begin{tabular}{|c|c|c|c|c|c|}
\hline Escolaridade após 2005 & 2006 & $\%$ & 2016 & $\%$ & TCAC \\
\hline Analfabeto & 123 & $0,09 \%$ & 34 & $0,03 \%$ & $-11,03 \%$ \\
\hline Fundamental (Completo e Incompleto) & 20.099 & $14,30 \%$ & 7.378 & $5,92 \%$ & $-8,71 \%$ \\
\hline Médio (Completo e Incompleto) & 94.844 & $67,50 \%$ & 86.929 & $69,71 \%$ & $-0,79 \%$ \\
\hline Superior (Completo e Incompleto) & 25.305 & $18,01 \%$ & 29.800 & $23,90 \%$ & $1,50 \%$ \\
\hline Mestrado & 118 & $0,08 \%$ & 485 & $0,39 \%$ & $13,71 \%$ \\
\hline Doutorado & 21 & $0,01 \%$ & 77 & $0,06 \%$ & $12,54 \%$ \\
\hline Total & 140.510 & $100,00 \%$ & 124.703 & $100,00 \%$ & $-1,08 \%$ \\
\hline
\end{tabular}

Fonte: Elaboração pelos autores com base na RAIS-MTE.

Ao mesmo tempo, seguindo a tendência das tabelas anteriores, a Tabela 6 mostra que as Classes tiveram uma expansão na escolaridade superior à Divisão 26. Aqui, mais uma vez, se evidencia a necessidade de maior qualificação, uma vez que, o grosso da mão-de-obra é do estrato Superior (completo e incompleto) e emprega em termos absolutos mais do que o estrato Médio da Divisão 26 (135.187 contra 86.929). Se evidencia maior expansão dessa atividade relativamente em função das maiores TCAC em todos os extratos e principalmente dos estratos Superior, Mestrado e Doutorado vis-à-vis aos mesmos extratos na Divisão 26. Em outros termos, as Classes se habilitam mais em termos de capacitação do que a Divisão 26. Esse fato apresenta lógica na medida em que, como já dito, é uma atividade de maior intensidade do conhecimento e nesse caso, está se capacitando mais para a sua produção, o que aumenta sua capacidade absortiva.

Tabela 6 - Grau de Escolaridade nas Classes 6201-5; 6202-3; 6203-1 - Desenvolvimento de Softwares - 2006-2016

\begin{tabular}{l|c|c|c|c|c}
\hline Escolaridade após 2005 & $\mathbf{2 0 0 6}$ & $\mathbf{\%}$ & $\mathbf{2 0 1 6}$ & $\mathbf{\%}$ & TCAC \\
\hline Analfabeto & 15 & $0,03 \%$ & 15 & $0,01 \%$ & $0,00 \%$ \\
\hline Fundamental (Completo e Incompleto) & 1.821 & $3,30 \%$ & 1.926 & $1,12 \%$ & $0,51 \%$ \\
\hline Médio (Completo e Incompleto) & 17.585 & $31,91 \%$ & 32.950 & $19,19 \%$ & $5,87 \%$ \\
\hline Superior (Completo e Incompleto) & 35.552 & $64,52 \%$ & 135.187 & $78,73 \%$ & $12,91 \%$ \\
\hline Mestrado & 97 & $0,18 \%$ & 1.438 & $0,84 \%$ & $27,78 \%$ \\
\hline Doutorado & 31 & $0,06 \%$ & 191 & $0,11 \%$ & $17,97 \%$ \\
\hline Total & $\mathbf{5 5 . 1 0 1}$ & $\mathbf{1 0 0 , 0 0 \%}$ & $\mathbf{1 7 1 . 7 0 7}$ & $\mathbf{1 0 0 , 0 0 \%}$ & $\mathbf{1 0 , 8 9 \%}$ \\
\hline
\end{tabular}

Fonte: Elaboração pelos autores com base na RAIS-MTE.

Em síntese, os dados demonstram que na "Indústria de TI" no Brasil as atividades de maior intensidade do conhecimento que são as Classes evoluíram de forma mais intensa do que as atividades da Divisão 26 que se referem à produção industrial de equipamentos em geral que implicam menores requisitos de intensidade do conhecimento. Neste sentido, a expansão das Classes é um sinal da disponibilidade de uma base "industrial" importante possível ou em aptidão crescente a desenvolver atividades de IoT. Uma política industrial vertical em determinadas atividades potenciais de crescimento de IoT teria amplo campo de desenvolvimento. Seria necessária uma pesquisa no âmbito das firmas potenciais desenvolvedoras de IoT a serem escolhidas nos moldes dos potenciais "campeões".

\section{O QUE PRETENDE A NATUREZA DA POLÍTICA INDUSTRIAL DE IoT DO ATUAL GOVERNO?}

Em 2016 o BNDES lançou a Chamada Pública BNDES/FEP Prospecção nº 01/2016 - Internet das Coisas (Internet-of-Things - IoT) que teve como objetivo "selecionar propostas para obtenção de apoio financeiro não reembolsável para a realização de Estudos Técnicos independentes com objetivo de realização de diagnóstico e proposição de políticas públicas no tema Internet das Coisas (Internet-of-Things - IoT)". O consórcio vencedor foi o formado por McKinsey \& Company, Fundação CPqD e Pereira 
Neto|Macedo Advogados ${ }^{5}$. Recentemente, publicou-se o resultado dos estudos contendo 27 relatórios detalhando atividades e resultados diversos da pesquisa. A metodologia de levantamento das informações baseou-se, fundamentalmente, na formação de painéis de especialistas, consultas públicas, entrevistas além da realização de workshops. Destaca-se a princípio o papel a ser assumido pela demanda. A frase-síntese do estudo mostra qual seria a aspiração do Brasil em IoT: "Acelerar a implantação da Internet das Coisas com instrumento de desenvolvimento sustentável da sociedade brasileira, capaz de aumentar a competitividade da economia, fortalecer as cadeias produtivas nacionais, e promover a melhoria da qualidade de vida". Essa frase reflete o fato de o estudo não possui uma espinha dorsal teórica: apresentase mais como um sistema de gestão da informação para geração de diretrizes. Assim, é predominante uma concepção difusa de demanda, que pode indicar diversos caminhos a partir de interesses particulares (depende da visão de mundo dos respondentes à pesquisa) do que uma concepção estruturada de desenvolvimento.

Ocorre que a partir de algumas atividades de consultas e dos painéis surgiu também a percepção de que mais importante que o lado da demanda, fazia-se necessário o levantamento sobre a capacidade da oferta. Qual o potencial de desenvolvimento de IoT no país? A partir dessa constatação, no Produto $3^{6}$ há um levantamento sobre tal potencial. O estudo parte de uma divisão técnica sobre as camadas de IoT, a saber: Dispositivos, Redes, Suporte a Serviços e Aplicações e Segurança. Dentro de cada camada há um conjunto extenso de subcamadas, as quais seriam as atividades produtivas especificas em IoT. Para cada camada, o estudo aponta que existem firmas estabelecidas (incumbentes) e aponta entrantes, isso indica que se trata de uma corrida ainda não definida. Entretanto, há uma premência, pois, o estudo mostra que já existe um número considerável de multinacionais atuando no mercado brasileiro, e que, a julgar pelas menções feitas nas consultas, estão se tornando rapidamente as líderes da atividade. A partir das firmas incumbentes e das entrantes mapeadas, é importante definir suas reais atividades e as possibilidades efetivas de geração de externalidades para a economia nacional. A questão é: em que medida tais atividades são capazes de criar capacitações internas e geração de competitividade da indústria, como um todo, a partir de efeitos de spillover?

Há todo um plano de ação e subsídios para o Plano Nacional de IoT que será lançado em breve e não há maiores informações a respeito dos desdobramentos pretendidos. Entretanto, é importante pensar sobre o significado do lançamento e as bases desse Plano. Conforme visto na Política de Informática, como exemplo, o BNDES, historicamente, teve uma atuação central na elaboração e execução da política industrial no Brasil. No período mais recente se tornou um dos 10 maiores bancos de investimento do mundo. Sua capacidade de atuar na gestão e direcionamento do investimento público e privado é algo que não pode ser ignorado. O Banco também criou um corpo de funcionários com elevada competência técnica nas mais diversas áreas, a refletir sobre desenvolvimento nacional, e com formação nos centros que pensam o tema. Nesse sentido, é curioso um estudo de fundamental importância para o desenvolvimento nacional ter sido liderado por uma consultoria privada multinacional, aliada a um escritório de advocacia, com aval do Banco a partir do Edital. Não há razões plausíveis de se fazer estudos sobre o desenvolvimento nessa perspectiva, considerando que se trata de políticas públicas e que há expertises dentro do Banco capazes de criar estruturas proativas na articulação institucional dentro do Estado. Tal fato ocasionou, como mencionado, um estudo sem bases do pensamento teórico compatível com política industrial, incapaz de indicar em suas diretrizes o propósito em termos do desenvolvimento nacional. No fim das contas, produzse um resultado com muitas informações relevantes, sem clareza quanto aos objetivos em termos desse desenvolvimento nacional.

Mais um elemento que não deixa claro a ideia sobre a política industrial do estudo é a visão sobre a organização dos setores da economia. Ao invés de adotar os conceitos de setor, sistema ou complexo que poderiam encontrar compatibilidade com as bases de dados da CNAE 2.0 e a partir de aí pensar em firmas

5 Disponível em: https:/www.bndes.gov.br/wps/portal/site/home/conhecimento/pesquisaedados/estudos/estudo-internet-dascoisas-iot.

6 Análise de oferta e demanda - Relatório - Análise da Oferta: https://www.bndes.gov.br/wps/wcm/connect/site/6c597bfe-b92d4084-ab07-5498e1ae2445/produto-3-analise-de-oferta-e-demanda-relatorio-parcial-analise-de-

demanda.pdf?MOD=AJPERES\&CVID=1SZJkHO. 
nacionais versus estrangeiras e/ou lideres $\mathrm{x}$ marginais de forma formular a política com prioridades, o estudo adotou a ideia de "Ambientes". Este conceito de "Ambientes" que não parecer ter referência na literatura de organização industrial abrange usuários, ofertantes e demandantes de IOT no que poderia ser um complexo industrial, mas não diferencia a natureza da oferta, apenas entende que é importante que o desenvolvimento da IOT (independente da forma que se organiza a estrutura de mercado) "melhore a vida dos 4 Ambientes que foram divididos em Saúde, Cidade, Rural e Indústria".

Em síntese o que se percebe é que se trata de um estudo que subsidia políticas a serem lançadas no apagar das luzes de um governo. Teria, assim, sentido para o desenvolvimento nacional que interesses privados subsidiem elementos para uma política industrial dessa ordem? Qual a relevância no contexto mais amplo das políticas industriais do país? Política industrial, afinal, pressupõe uma visão de desenvolvimento, que não é encontrada no estudo.

\section{CONCLUSÃO}

Este artigo mostrou que historicamente o Estado sempre teve papel central em definir as diretrizes e a direção do desenvolvimento econômico. A referência de Mazzucato (2013) é central para recuperar a visão do Estado keynesiano na gestão da demanda, tomador de risco e criador de mercado. O Estado assume, papel primordial nos sistemas de inovação, facilitando e propiciando condições para o processo inovativo. O risco assumido pelo Estado se relaciona ao fato que a difusão de inovações não é linear, os papéis da educação, formação, design, controle de qualidade e demanda efetiva assumem posições tão importantes quanto o sistema de P\&D interno à empresa. E nisso o Estado toma para si essas atividades.

Conforme se pode concluir a partir dessas referencias o Estado no Brasil teria um papel mais central em direcionar o desenvolvimento uma vez que conforme Chang (2002) os países desenvolvidos estariam atuando para "chutar a escada". Ou seja, eles "subiram a escada" a partir do Estado e da política industrial, alcançaram o desenvolvimento e agora pregam o Estado Mínimo e a eficiência do setor privado para os países em desenvolvimento. O caso de sucesso da Apple nunca aparece como um caso em que o Estado teve papel central. Logicamente não se despreza o papel de inovador de Steve Jobs, mas os investimentos públicos deram a base tecnológica, o capital de risco e incentivos fiscais.

Nessa linha de forte atuação do Estado se argumenta no artigo que nos anos 70/80 o Estado brasileiro teve forte atuação na definição e condução da Política de Informática. O ponto central é que se verifica a ampla articulação institucional no âmbito do aparelho de Estado. A Política de Informática tem seu início a partir de um contrato entre a Marinha, o Ministério do Planejamento e universidades e criação do projeto GTE/FUNTEC 111. Também foi criada a CAPRE, sendo responsável por colocar em prática políticas governamentais para o setor de informática. Era uma articulação institucional que envolvia Ministério do Planejamento, Forças Armadas, Ministério da Fazenda, BNDE, SERPRO, IBGE e Escritório da Reforma Administrativa. Uma das diretrizes dessa Comissão e que mais tarde se tornou o eixo central da Política Nacional de Informática era a "capacitação de organizações industriais brasileiras no desenvolvimento e fabricação dos equipamentos (hardware)" (Fajnzylber, 1993, p. 5). A partir dessas ações houve uma relativa profusão de produção nacional com parcerias e licenciamentos de firmas estrangeiras: Sycor 400 da COBRA, Sharp/Inepar/Dataserv com tecnologia da Logabax francesa, a Edisa com tecnologia da Fujitsu japonesa e a Labo com tecnologia da Nixdorf alemã. Porém em 1991, o então presidente Fernando Collor, acabou com a Política de Informática, colocando fim aos aparatos institucionais e aos instrumentos da política.

Entretanto, ao longo dos anos 90 e 2000 com todo o mecanismo crescente de desmonte do Estado, privatizações e fim das políticas públicas a economia brasileira construiu uma "indústria de TI". Os dados da RAIS/MTE mostram no período 2006/16 uma expansão importante da área de fabricação de hardware e principalmente de software, tanto em termos de expansão do número de estabelecimentos, emprego e capacitação. As atividades mais ligadas a produção de software tiveram expansão mais expressiva o que indica elevado potencial dessas atividades se voltarem à produção de atividades de IoT.

A partir da perspectiva de lançamento em breve de uma Política Nacional de IoT pelo Governo Federal foi importante resgatar os elementos anteriores para a sua análise. O Estudo do BNDES apesar de trazer importantíssimos elementos de natureza técnica sobre o potencial de desenvolvimento de IoT no país é mais uma gestão de informações para a definição de diretrizes técnicas. Entretanto, como visto 
anteriormente política industrial implica organização institucional e para isso é necessária definição de natureza política sobre a atuação do Estado. Desse modo, há uma incompatibilidade entre a origem do estudo e o significado de uma política industrial. Em outros termos, política industrial significa articulação e criação de estruturas de poder dentro do Estado. Estas estruturas ganham poder no sentido do conhecimento quanto na capacidade de estabelecer a direção da política. O Estado neste caso claramente não é neutro. Ele assume uma direção. Uma vez que o estudo é feito por um consorcio privado não há as mínimas condições para que ele possa indicar os mecanismos de reorientação do Estado. Ao mesmo tempo, o estudo é uma ruptura com o padrão anterior de elaboração de política, tanto na perspectiva de que não tem uma fundamentação teórica que discuta política industrial e desenvolvimento como busca a definição de política industrial no setor privado, quando no BNDES, por exemplo, estão instaladas amplas competências técnicas para pensar e elaborar subsídios de políticas públicas. Ademais a partir do estudo esta perspectiva do lançamento de uma suposta Política Nacional de IoT no apagar das luzes da atual gestão do Governo Federal lança uma nevoa para apresentar uma política que na verdade é para não haver política.

\section{REFERÊNCIAS}

ALDER, E. Ideological "Guerrillas" and the Quest for Technological Autonomy: Brazil's Domestic Computer Industry. Journal Storage, source International Organization Vol. 40 n 3, 1986. pp.673705 .

CHANG, H.J. (2002). Kicking away the ladder: development strategy in historical perspective. Londres:Anthem Press. (PORTUGUES) CHANG, H.J. The Political Economy Of Industrial Policy. New York: St. Martin's Press, 1994.

EVANS, P. Embedded Autonomy: States and Industrial Transformation. Princeton, NJ, Princeton University Press, 1995.

FAJNZYLBER, Pablo. A Capacitação Tecnológica na Indústria Brasileira de Computadores e Periféricos: do Suporte Governamental à Dinâmica do Mercado. Dissertação de Mestrado UNICAMP. $1993 . \quad$ Disponível em: <http://repositorio.unicamp.br/jspui/bitstream/REPOSIP/286491/1/Fajnzylber_Pablo_M.pdf> Acesso em: 28/03/2018.

FURTADO, JOÃO (RESPONSÁVEL); PINHEIRO, HENRIQUE; URIAS, EDUARDO \& MUÑOZ, DIEGO. Indústria 4.0: a quarta revolução industrial e os desafios para a indústria e para o desenvolvimento brasileiro. julho/2017. http://www.iedi.org.br/media/site/artigos/20170721_iedi_industria_4_0.pdf. Acesso 13/04/18

GADELHA, C.A.G. Estado E Inovação: Uma Perspectiva Evolucionista. 2002. Disponível em: <http://www.ie.ufrj.br/images/pesquisa/publicacoes/rec/REC\%206/REC_6.2_04_Estado_e_inovacao_ uma_perspectiva_evolucionista.pdf> Acesso em: 02/09/2013.

KRUGMAN, P.R. (1989). Industrial organization and international trade. In: SCHMALENSEE, R.; WILLIG, R. (Eds.). Handbook of industrial organization. New York: Elsevier.

KUPFER, D. (2003). Política industrial. Econômica, Rio de Janeiro, v. 5, n. 2, p. 281-298

MAZZUCATO, Mariana. The Entrepreneural State: Debuking Public vs. Private Sector Myths. 2013, Editora Anthem Press.

RODRIGUES, Helena S. Rastro de Cobra. Rio de Janeiro: Caio Domingos \& Associados Publicidade LTDA, 2004. 
TIGRE, P. B. Ciência e Tecnologia no Brasil: Uma Nova Política para um Mundo Global liberalização e capacitação tecnológica: o caso da informática pós-reserva de mercado no Brasil. Instituto de Economia Universidade Federal do Rio de Janeiro. Rio de Janeiro. 1993

Sites pesquisados:

IBGE - Pesquisa Industrial Anual - Empresa

https://www.ibge.gov.br/estatisticas-novoportal/economicas/industria

RAIS - Relação Anual de Informações Sociais

http://bi.mte.gov.br

BNDES (2016)

https://www.bndes.gov.br/wps/portal/site/home/conhecimento/pesquisaedados/estudos/estudo-internetdas-coisas-iot

http://www.valor.com.br/empresas/5400829/plano-de-\%3Finternet-das-coisas\%3F-sera-lancado-em-abrildiz-governo 